\title{
Re-engineering Construction Work-processes for Building Automation
}

\author{
Roozbeh Kangari* \\ *Associate Professor, Civil Engineering School, Georgia Institute of Technology, Atlanta, \\ GA 30332, USA
}

\begin{abstract}
To develop a cost effective building automation system, there is a need for new way of thinking. Automating the traditional construction operations most likely would not result in a sustainable and profitable sy stem. We must develop the automated sy stems in the context of construction work-processes rather than traditional work functions. The objective of this paper is to propose new ideas and ways of designing construction automation system by focusing on work-processes and Computer Integrated Construction (CIC).
\end{abstract}

\section{INTRODUCTION}

This paper describes the conœpts of construction work-processes as they relate to building automation. The future success of construction firms may well depend on the widespread implementation of Computer Integrated Construction (CIC) conœpts. Because of changes in the competitive environment, the nature of the construction industry is evolving in fundamental way s. Construction companies that emphasize CIC are likely to gain a significant competitive advantage over those that do not. In today's construction industry, information technology must be viewed as a potential resource. CIC is a strategy, incorporating computers and robotics, for linking existing technology and people in order to optimize business activity. A strategy for implementing CIC has been formulated, however each company must define its own system. The strategy must be supported and promoted at the highest company level. Construction technology innovation is becoming an increasingly important factor for the growth of many large firms. It has become essential that new construction technologies be identified, obtained on the most reasonable terms, and transferred smoothly to the construction site. The increasing globalization of technology and economy in an environment of overwhelming competition and cutbacks in public resources are expected to have a considerable impact on the future of technology research centers. The framework for developing innovative construction technology can be defined as: identify ing and selecting high potential construction processes for innovation, identify ing innovative technologies for new construction process design, defining the firm's strategy and vision, understanding the structure and flow of the current construction procss, measuring the productivity of the 
current construction method, designing the new construction process, prototy ping the new technology, implementing the innovative technology, collecting information and communicating ongoing results of the effort, building commitment toward the solution at each step of the technology implementation.

Despite its promise to provide a competitive edge to companies that use it, innovative technology development is still a rare phenomenon in the construction world. A growing number of firms in the world are aware of its existence, but very few have undertaken serious initiatives to implement it. The reason for this is simple: construction technology innovation requires a large amount of capital and resources, so the conservative construction industry does not embrace it. One solution to the high cost of developing new construction technology has initially been to apply the technology to a small set of projects in order to gain experience with innovative technology initiatives, and then focus resources on the most critical processes such as large scale material handling. Therefore, how essential that technology is to the execution of the firm's main line of construction is a key factor in the development of innovative technology. Another solution to the high cost of new construction technology development is simulation modeling. It allows the simulation of the design and construction proœss of new technology in increasingly realistic and complex settings. 3-D graphics workstations can be successfully used to display material movement in relation to other components and to simulate effects of hostile environments, resource constraints, and rapid design and construction.

\section{CONSTRUCTION PROCESS TECHNOLOGY}

In the 1992 Peurifoy Construction Research Lecture (Halpin 1992), it was indicated that the basis for the theory of construction operations and the study of construction lies in the area of process modeling. Lack of interest in studying process technology is one of the major reasons why most innovation in methods and techniques have been developed outside of the U.S. In the 1990s and beyond, there will be an explosion of new and innovative construction process technology. Since construction is a process based industry, therefore the construction methods and processes must be improved. But in order to develop new processes, we must better understand the present processes which are in place. Moreover, innovation and process improvement require a framework or notation in terms of which processes can be studied and improved. Technology and more specifically construction process technology will be the key to leadership in world construction market. A framework for the study of construction processes must be developed so that greater innovation in construction methods can be realized to support construction of increasingly complex projects. There is a need for developing an analytical framework for the study of construction processes.

This author's investigation on building automation technology has led to the similar conclusions that development of a framework for understanding the construction process innovation is the key for technology innovation and more specifically automation technology which could increase dramatically the productivity of a construction site. 
Therefore, this investigation was focused on better understanding of innovative construction work processes and technologies.

The term construction process innovation encompasses the envisioning of new work strategies, the actual process design activity, and the implementation of the change in all its complex technological, human, and organizational dimensions. Defined simply, innovation is the introduction of something new. It is presumed that the purpose of introducing something new into a construction process is to bring about major, radical change. Construction process innovation should be distinguished from process improvement, which seeks a lower level of change. If construction process innovation means performing a work activity in a radically new way, process improvement involves performing the same construction process with slightly increased efficiency or effectiveness.

Construction process innovation is the adoption of a process view of the construction with the application of innovation to key construction processes. What is new and distinctive about this combination is its enormous potential for helping any construction firms to achieve major reductions in process cost or time, or major improvements in quality, flexibility, service levels, or other business objectives.

Construction process innovation also implies the use of advanced technologies and tools. One of these, information/automation technology, has been considered by many as the most powerful tool for changing the construction industry to emerge in the twentieth century. The dramatic capabilities of computers and communications are powerful technologies for construction process innovation.

Investigation of the Japanese automation technology shows that they have focused on innovating the most critical processes, and each successful initiative has become a model for future efforts. They have focused on the process's centrality to the execution of the firm's business strategy. For example, a company specializing in the building construction, considers the construction of the building structure as its central process. Therefore, innovating the construction work process for building structure becomes the focus of research.

The proposed framework for construction process innovation consists of five steps: identifying potential work-processes for innovation, identifying change enablers (technologies), developing work-process objectives, understanding and measuring existing work-processes, and designing and building a prototype (e.g. 3-D simulation) of the new work-process and organization. Construction process innovation must begin with a survey of the process to identify processes that are candidates for innovation. Both the overall listing of work-processes and the focus on those requiring immediate innovation initiatives are crucial to the success of innovation efforts. The most obvious approach to process selection is to select the processes most central to accomplishing the organization's strategy: Identify potential technological and human opportunities for process change, and identify potentially constraining technological and human factors. Having identified potential opportunities and constraints, their relevance to the process under analysis must be determined. Opportunities must be researched to determine how the technological or human innovation might be employed in the process. 


\section{AUTOMATED CONSTRUCTION WORK PROCESS INNOVATION}

Investigation of various automated building systems has shown that the process of Material Movement dictates other operations. In another words, study of material movement process becomes a major and critical issue in the development of an automated system.

This author proposes that the Critical Process of a construction activity shall be Material Movement Process which consists of: 1) Material prefabrication process, 2) Material transportation (to the site) process, 3) Material storage process, 4) Material handling (in the site) process, and 5) Material installation process. This indicates that a construction project should be planned based on the above five processes, rather than traditional method of dividing a project into activities (e.g. concrete work, masonry work, and others).

Building a project based on the Material Movement Process would revolutionized the construction work. It would provide a framework for developing innovative ideas and technologies. Material movement processes, which involves the movement and installation of construction materials, are extremely important to successful project delivery. The past decade has seen considerable growth in the perceived importance of integrated material movement processes.

Success in material movement is largely turns on the application of a process perspective. Decisions along the material movement chain have resulted in a decided competitive advantage. The construction industry should consider the material movement in an integrated fashion, rather than from a functional perspective. Contractors should make decisions not based on functional and traditional construction activity performance or the cost/profit center concept, but on the material movement perspective.

\section{WHY MATERIAL MOVEMENT PROCESS}

Planning a project by the material movement process allows the contractor to become innovative by considering: Information technology, automating work processes, capturing process information for better understanding, changing process sequence or enabling parallelism closely monitoring process status and objects, improving analysis of information and decision making, coordinating processes across distances, coordination between tasks and processes. The most commonly recognized benefit of information technology is its ability to automate and produce a more structured process. Information technology can be used within a process to capture information about process performance, which can then be analyzed by contractor.

Information technology can enable changes in the sequence of processes or transform a process from sequential to parallel in order to achieve process cycle-time reductions. This opportunity is at the core of the concurrent engineering and design/build phenomenon. Tracking to effectively execute material movement process requires a high degree of monitoring and tracking. Knowing the status of material throughout the pipeline permits the firm to avoid bottlenecks. 
Material movement processes involve analysis of information and decision making, and it can bring an array of sophisticated analytical resources that permit more data to be incorporated in and analyzed during the decision-making process.

Information technology supports rapid design of many components and processes, in both two and three dimensions, for the $\mathrm{A} / \mathrm{E} / \mathrm{C}$ firms. Simulation technology enables process designers to simulate the execution of designs in increasingly realistic and complex settings. In product design, 3-D graphics workstations can display component movement in relation to other components and simulate stress loading and effects of hostile environments; in process design, the implications of resource constraints and the ability of processes to run faster and to handle increased volume can be interactively simulated. In complex material movement processes, managers must be able to track continuously the status of particular material. Future enhancements to tracking systems are expected to support graphic representation, provide early warnings of resource constraints, and facilitate ease of use and understanding by nontechnical managers.

Key to material movement processes is knowing the location of materials or equipment within a geographical network. Sophisticated computer and communications technologies are increasingly being used to rapidly and accurately determine the location of materials, equipment, and people. Although information and information technology together constitute a formidable enabler of process change, they are not the only factors that can lead to radical process change. People - both as individuals and in organizations - are also a major enabler of change.

Developing a prototype is a way to simulate and test the operation of a material movement process. It is an iterative process in which the fit between new process structure, information technology, and organization is refined and re-refined. A prototype might be considered the analog of a scientific experiment performed in a lab.

Material movement process innovation is characterized by simultaneous dramatic change in many structures and systems. For example, the concept of just-in-time (JIT) is a method of improving the material storage process, or using an automated material handling system in a construction site is one way of improving the Material Handling Process. Another example is automated welding or prefabricated systems which are improved components of the Material Installation Process.

Using the concept of Material Movement Process, the following steps will assist in developing innovative processes:

- identifying and selecting sub-processes for redesigning material movement;

- identifying enablers (technologies) for new material movement sub-process design;

- defining sub-process vision;

- understanding the structure and flow of the current material movement process;

- measuring the performance of the current material movement process;

- designing the new material process;

- Prototyping the new material movement process;

- implementing and operationalizing the material movement process and associated systems. 
Ideally, a tool chosen for new material movement process design should be capable of:

- graphically portraying the material movement process steps;

- depicting the flow of materials and information between steps;

- accepting and portraying flow rate, resource and time consumption, and capacity and/or trigger information for each material movement process step;

- rolling up or exploding the steps of the material movement process in a hierarchical fashion to accommodate varying levels of detail;

- presenting a highly interactive and preferably graphical user interface;

- running live simulations and producing real-time graphical output for material movement processes;

- identifying key bottlenecks and constraints in the material movement process.

Information technology plays an important role the implementation of process innovation. The success of material movement process innovation often lies in the speed with which it can be accomplished; failure to employ information technology enablers can substantially compromise design and implementation speeds. The following section shows a list of enablers (technologies) which could assist implementing a Material Movement Process:

- Computer-aided engineering and design

- Data gathering and analysis tools

- Decision analysis software

- Desktop graphics tools

- Executive information systems

- General communications technologies

- Group decision-support systems

- Hypermedia

- Idea generation tools

- Information engineering

- Object-oriented programming

- PC-based prototyping tools

- Process modeling tools

- Programmable databases and spreadsheets

- Project management tools

- Prototyping

- Rapid systems development techniques

- Simulation

- Strategic application databases

- Systems engineering products

- Technology trend databases

- Knowledge based systems

Information technology and robotics are key for the development of an innovative material movement process. The relationship between information technology and processbased material movement is reciprocal; material movement processes require information 
technology to achieve radical change, and to harness the capabilities of information technology in a cross-functional, performance-driven manner requires a process view. Information technology can both provide opportunities for and impose constraints on material movement process innovation. Opportunities take a variety of forms, including automational. Information technology and material movement process together can be used to better integrate process activities both within a process and across multiple processes.

\section{LESSONS LEARNED}

The investigation shows that usually the initial problem management faces is the lack of a methodology to explore a CIC initiative. It is important to develop the theoretical substructure for CIC implementation. Given the complexity of the problems in the construction industry, it is not useful to seek final CIC solutions. Rather, managers must establish a leaming environment that will continually guide the company toward improved sy stems.

It is essential to recognize that moving toward a CIC system does not mean simply introducing higher levels of computers and automation into an existing system. Adding automation to an inefficient sy stem will likely produce a highly automated, inefficient sy stem.

It is also important, when talking about CIC, to include not only the construction and design but also other activities. The overall system must be rationalized, requiring that the work flow, organizational structure, and management methods be redesigned to obtain performance objectives. The entire meaning of design must be assessed and modified as necessary to optimize sy stem performance (Tucker et al. 1986). The most appropriate use of technology can then be selected within this context.

Introduction of CIC has provided the company with a new philosophy toward the application of advanced technologies to construction sites. It is believed that meeting such a challenge can make a company more competitive in the world market.

$\mathrm{CIC}$ has also presented changes in working practice. Job descriptions are becoming more multidisciplinary due to the integration of different functions. As the CIC project progresses through its different phases, the skill mix and roles of the team members change. In the early stages when the requirements are being planned and the concept designed, the work is more exp loratory and analy tical. During detailed design and implementation, it is more technical.

Although it is difficult to achieve a JIT sy stem, the philosophy presents a perfect target to have in mind when implementing CIC. In developing this technology, the main goal was defined as productivity improvement through:

- Introduction of new construction methods and prefabricated design

- Efficient use of resources

- Reduction in the design-construction cy cle

- Improvement in Constructability

- Reduced construction material inventories by application of the Just-in-Time (JIT) philosophy

- Better quality control and reduction in wastage 
- Excellent internal and external communication and effective linkage with material suppliers and prefabrication plants

To accomplish the goal, this emerging technology was applied to the following principles of technological innovation:

- The synthesis of two technologies (i.e., the automation and construction procsses) and technological intelligence regarding the potential for construction automation of building facilities

- The collaboration of two firms with different core competence

- An emphasis on technology development and commercial application, and rapid commercialization of technology

- Organizational leaming through horizontal information exchange and accumulation

- The consolidation of diverse technologies through joint ventures, and rapid diffusion of technology horizontally to many applications in building construction

- Continuous improvement in the technology

\section{CONCLUSIONS}

Three basic principles that have been essential to innovative construction technology synthesis are that large construction firms have excellent information gathering capabilities; these companies invest in research consortia, joint ventures, and partnerships; and the clients have generally supported the innovative technologies. The joint capabilities and strengths of the two prospective parents benefit both partners. The combination of forcs has enabled both partners to experience a win-win situation. The following list provides the framework for developing innovative construction:

- Identify ing and selecting high potential construction processes for innovation (e.g, sted erection, material handling, and automated welding)

- Identify ing innovative technologies for new construction process design (e.g, CAD/CAE, robotics, and the computer)

- Defining the firm's strategy and vision (e.g, to be a leader in automating building design and construction)

- Understanding the structure and flow of the current construction procss (e.g, traditional steel erection by cranes)

- Measuring the productivity of the current construction method (e.g, productivity data of traditional methods of building construction)

- Designing the new construction proœss (e.g, automated material handling)

- Prototy ping the new technology

- Imp lementing the innovative technology

- Collecting information and communicating ongoing results of the effort (e.g, collection of a large database of construction process times and productivity)

- Building commitment toward the solution at each step of the technology implementation

Despite its promise to provide a competitive edge to companies that use it, innovative technology development is still a rare phenomenon in the construction world. A growing number of firms in the world are aware of its existence, but very few have undertaken serious 
initiatives to implement it. The reason for this is simple: construction technology innovation requires a large amount of capital and resources, so the conservative construction industry does not embrace it.

One solution to the high cost of developing new construction technology has initially been to apply the technology to a small set of projects in order to gain experience with innovative technology initiatives, and then focus resources on the most critical procsses such as sted erection and large scale material handling. Therefore, how essential that technology is to the execution of the firm's main line of construction is a key factor in the development of innovative technology .

Another solution to the high cost of new construction technology development is simulation modeling. It allows the simulation of the design and construction process of new technology in increasingly realistic and complex settings. 3-D graphics workstations can be used to display material movement in relation to other components and to simulate effects of hostile environments, resource constraints, and rapid design and construction.

In the next decade, implementation of Computer Integrated Construction (CIC) is expected to play an important role among the large construction companies. One reason for this is that, using CIC, it is likely that a completely different and more efficient construction operation may be developed. The other reason is the tremendous advantage to be gained by enabling computers in different sectors of the company to communicate and exchange information.

In today's construction industry, information technology must be viewed as a potential resource. CIC is an emerging technology, and also an approach to assisting construction firms in responding to the difficult environment in which they currently operate. There is no standard formula for CIC. However, a strategy for implementing CIC should be formulated, and each company must define its own system. The strategy must be supported and promoted at the highest company levels. The implementing director needs a clear policy relative to three issues: Justifications for CIC; longterm commitment to computers and robotics; and the impact of CIC on the work forœ.

It is believed that CIC will result in changing the work habits of a company's workforce. Job descriptions will become more multidisciplinary due to the integration of the different functions. For these changes to take place smoothly, the workforce must be informed of management's intention to implement CIC technology, and requisite training must be offered.

\section{REFERENCES}

Ansel, E.O. (1993). "Technology Transfer Caltech-Style." les Nouvelles, Journal of the Licensing Executives Society, vol. XXVIII, no. 1, pp. 10-12, March.

Benghozi, P.J. (1983). "Comment evaluer les politiques d'aide a l'innovation?" Politiques et Management Public, vol. 1, no. 3, pp. 79-99, 1983.

Choi, K.C., and Ibbs, C.W. (1989). "Cost Effectiveness of Computerization in Design and Construction." CII Source Document 50, University of Texas at Austin, August. 
Ditzel, R.G. (1990). "Commercializing University Technology." les Nouvelles, Journal of the Licensing Executives Society, vol. XXXV, no. 4, pp. 176-179, December.

Hakansson, H., and Londres, R. (1989). "Industrial technological development: A network approach." Collection Management and New Information, vol. 1, no. 3, pp. 240-245.

Halpin, D.W. (1993). "Process-Based Research to Meet the International Challenge." ASCE Journal of Construction Engineering and Management, Vol. 119, No. 3, pp. 417-425, Peurifoy Construction Research Lecture presented September 1992, at the ASCE Annual Convention held in New York.

Halpin, W.P., and Woodhead, R.W. (1976). "Design of Construction and Process Operations." John Wiley \& Sons, New York, N.Y.

Hasegawa, Y. (1994). "Developments and Trends of Construction Robotics in Japan." Procedings of the 25th ISIR Conference, Hannover, Germany.

Kangari, R., and Yoshida, T. (1990). "Automation in Construction." Robotics International Joumal, Robotics and Autonomous Sy stems, Volume 6, 327-335.

Maitre, P., Miquel, J.D., and Brenet, P.(1992). De l'ldee au produit: Guide de la valorisation industrielle de la recherche. Editions Ey rolles, Paris.

Miege, R. (1993). "Strategic issues relevant to RTOs: Introductory Comments Speaker." Proceedings of the Future of Research and Technology Organizations Conference, DG XIII of the Commission of the EC, Brussels, November 16-17.

Miyatake, Y., and Kangari, R. (1993). "Experiencing Computer Integrated Construction." ASCE Joumal of Construction Engineering and Management, Volume 119, No. 2, June.

$R \& D$. (1992). Research and Development. Research and Development Report, Shimizu Corporation, Tokyo, Japan.

Sandelin, J. (1993). "Successful licensing of research results." les Nouvelles, Journal of the Licensing Executives Society, vol. XXVIII, no. 3, pp. 127-129, September.

Schmidt, T.K. (1990). "Technology as an instrument of competition" Informatik, vol. 37, no. 6 , pp. $215-218$.

System Cuts Labor Needs. (1991). Engineering News Record, McGraw-Hill Construction Weekly, November 11. 